A resiliência das cidades frente a chuvas torrenciais: Estudo de caso do plano de contingência da cidade do Rio de Janeiro Marisa Fasura de Amorim, Osvaldo Luiz Gonçalves Quelhas, Ana Lúcia Torres Seroa da Motta

\title{
A RESILIÊNCIA DAS CIDADES FRENTE A CHUVAS TORRENCIAIS: ESTUDO DE CASO DO PLANO DE CONTINGÊNCIA DA CIDADE DO RIO DE JANEIRO
}

\author{
The resilience of cities across the torrential rains: \\ Case study of the contingency plan of the city of Rio de Janeiro (Brazil)
}

Marisa Fasura de Amorim

Universidade Federal Fluminense, Niterói, Rio de Janeiro, Brasil mfasura@gmail.com

Osvaldo Luiz Gonçalves Quelhas Universidade Federal Fluminense, Niterói, Rio de Janeiro, Brasil quelhas@latec.uff.br

Ana Lúcia Torres Seroa da Motta Universidade Federal Fluminense, Niterói, Rio de Janeiro, Brasil anaseroa@hotmail.com

Artigo recebido em 01/02/2014 e aceito para publicação em 16/06/2014

RESUMO: A Defesa Civil do Estado do Rio de Janeiro elaborou um Plano de Ações onde uma das bases é a Estratégia Internacional para a Redução de Desastres-EIRD da Organização das Nações Unidas- ONU. Este Plano visa minimizar os grandes impactos ocasionados pelos desastres. No Rio de Janeiro as chuvas torrenciais que geralmente assolam o município no verão ocasionam grandes enchentes e deslizamentos. Este problema agregado às características do relevo e a ocupação desordenada da cidade afeta principalmente aos moradores das áreas de risco. Este artigo baseia-se na revisão da literatura com foco no referencial teórico do Plano de Contingência da Cidade do Rio de Janeiro - PEM-Rio.

Palavras-chave: redução de desastres; resiliência; plano de contingência.

ABSTRACT: The Civil Defense of the State of Rio de Janeiro has prepared an Action Plan which is the basis of the International Strategy for Disaster Reduction, ISDR of the United Nations UN. This Plan aims to minimize the impacts caused by major disasters. In Rio de Janeiro the torrential rains that usually plague the city in the summer cause massive flooding and landslides. This problem added to the characteristics of relief and disorderly occupation of the city affects mainly the residents of risk areas. This paper is based on the literature review focused on the theoretical framework of the Contingency Plan of the City of Rio de Janeiro - Rio-PEM.

Keywords: disaster reduction; resilience; contingency plan. 


\section{INTRODUÇÃO}

Evidências sobre mudanças climáticas têm atraído o setor público, a comunidade científica e a população em geral desde a década de 1980 representando um desafio para os gestores públicos (MARENGO, 2008; SANTOS et al, 2010; DAMÉ et al, 2013). Segundo estudos, esta situação foi gerada com o advento da revolução industrial que não só trouxe o crescimento econômico e demográfico para as grandes cidades mais também impactos ambientais (CORTESE, 2013).

Em 1988, a Organização Meteorológica Mundial (OMM) e o Programa das Nações Unidas para o Meio Ambiente (PNUMA) se uniram para criar o Painel Intergovernamental de Mudanças Climáticas - IPCC (Intergovernamental Panel on Climate Change). O IPCC tinha por objetivo apoiar trabalhos científicos quanto a informações técnicas e socioeconômicas relevantes voltadas ao atendimento aos riscos induzidos pelas mudanças climáticas que poderiam atingir a população humana. A credibilidade dos estudos das comunidades científicas agregado a políticas públicas eficientes poderiam reduzir os impactos advindos dos desastres naturais (MARENGO, 2008).
Segundo Oliveira (2011), desastre natural é todo fenômeno natural de grande intensidade, agravado ou não pela atividade humana. Dentre estes fenômenos estão às chuvas intensas que provocam inundações, erosão e escorregamentos. Para quantificação de chuvas intensas deve ser avaliado a quantidade de chuva incidente em um município ou mesmo em diferentes e distintas áreas da cidade. Esta variação pode implicar em maior ou menor impacto do fenômeno natural no local (OLIVEIRA, 2011; ULTRAMARI; HUMMELL, 2011).

No Brasil, os maiores desastres naturais estão relacionados aos danos causados por chuvas e secas intensas. Dados referentes a eventos relacionados a desastres naturais notificados à Secretaria Nacional de Defesa Civil entre os anos de 2007 a 2010 são apresentados na Tabela 1. O Rio de Janeiro foi o estado que apresentou o maior número de vítimas afetadas por desastres naturais no período de estudo. Previsões de precipitações para limiares acima de $50 \mathrm{~mm} / 24 \mathrm{~h}$ ainda apresentam baixos índices de acertos e dependem do conhecimento tácito do avaliador do centro de controle meteorológico. Medidas como ocupação ordenada do território, prevenção, monitoramento, alerta e preparo da população para situações de risco podem reduzir prejuízos e perdas de vida. (ULTRAMARI; HUMMELL, 2011; NETO, 2012).

Tabela 1. Desastres naturais notificados à Secretaria Nacional de Defesa Civil

\begin{tabular}{|l|c|c|c|c|c|c|c|c|c|c|}
\hline Estado & \multicolumn{2}{|c|}{2007} & \multicolumn{2}{|c|}{2008} & \multicolumn{2}{|c|}{2009} & \multicolumn{2}{|c|}{2010} & \multicolumn{2}{|c|}{ Total } \\
\cline { 2 - 10 } & A & B & A & B & A & B & A & B & A & B \\
\hline $\begin{array}{l}\text { Rio } \\
\text { Grande } \\
\text { do Sul }\end{array}$ & 123 & 279.088 & 146 & 467.538 & 492 & 77.564 & 136 & 406.282 & 897 & 1.230 .472 \\
\hline $\begin{array}{l}\text { Rio de } \\
\text { Janeiro }\end{array}$ & 75 & 769.231 & 64 & 615.061 & 113 & 10.404 .496 & 132 & 6.436 .182 & 384 & 17.674 .970 \\
\hline $\begin{array}{l}\text { Santa } \\
\text { Catarina }\end{array}$ & 20 & 61.869 & 94 & 114.307 & 61 & 2.073 & 155 & 739.324 & 330 & 947.573 \\
\hline $\begin{array}{l}\text { Rio } \\
\text { Grande } \\
\text { do Norte }\end{array}$ & 100 & 358.201 & 94 & 426.965 & 93 & 7.500 & 10 & 24.760 & 297 & 817.426 \\
\hline Piauí & 4 & 4.417 & 21 & 112.215 & 90 & 163.039 & 113 & 772.646 & 228 & 1.052 .317 \\
\hline
\end{tabular}

A- Desastres naturais notificados à Secretaria Nacional de Defesa Civil

B- Número de pessoas afetadas por acidentes naturais no estado

Organização dos autores 
A redução dos impactos ocasionados pelos desastres naturais relacionados principalmente aos fenômenos hidro meteorológicos como as chuvas, depende de um alinhamento junto a Defesa Civil. Estratégias integradas que auxiliem no zoneamento das áreas de risco, a implementação de sistemas de alerta, monitoramento e capacitação da população para emergências poderão auxiliar no processo (OLIVEIRA, 2011).

\section{A SITUAÇÃO}

A cidade do Rio de Janeiro possui características geográficas que possibilitam a ocorrência de precipitações pluviométricas intensas. Sua topografia é delineada por três maciços: Gericinó-Mendanha ao norte, maciço da Tijuca a leste e o maciço da Pedra Branca a oeste. As demais áreas da cidade são planícies, com uma altitude média de $20 \mathrm{~m}$. Ao sul é banhado pelo Oceano Atlântico, a leste a Baía de Guanabara e a oeste a Baía de Sepetiba. A média total anual de precipitações na Zona Oeste do município é de $1.200 \mathrm{~mm}$. Na Zona da Tijuca, estes valores aumentam consideravelmente alcançando $2.200 \mathrm{~mm}$, devido principalmente às características da região e sua proximidade com o mar. O crescimento desordenado e as construções em áreas de risco como morros e encostas contribuem para a ocorrência de deslizamentos, fatores que normalmente contribuem para haja mortos e feridos. Segundo estudos, as mudanças climáticas também têm ajudado a aumentar a frequência e a intensidade das chuvas fortes e/ou prolongadas no município (PEM-Rio, 2012; LUCENA, 2012; DERECZYNSKI et al, 2013).

Em janeiro de 2011, chuvas torrenciais atingiram a região serrana do estado deixando um rastro de 911 mortos e quase 35 mil pessoas desabrigadas. As cidades mais atingidas foram Teresópolis, Nova Friburgo e Petrópolis (Portal G1, 2011). Esta ocorrência impulsionou a implementação do Plano de Emergência para chuvas fortes da Cidade do Rio de Janeiro o PEM-Rio. Elaborado em 2012 pela Subsecretaria de Defesa Civil da Prefeitura da Cidade do Rio de Janeiro - SUBDEC tinha por objetivo garantir a integridade física dos moradores de áreas de alto risco estabelecendo procedimentos para a desocupação rápida e segura dos moradores. As bases legais que fundamentaram a elaboração do PEM-Rio são apresentadas na Tabela 2 (CENAD, 2012; PEM-Rio, 2012).

Tabela 2. Base legal do PEM-Rio

\begin{tabular}{|l|l|}
\hline Base legal & Características \\
\hline Protocolo de Hyogo & $\begin{array}{l}\text { Marco de Ação de Hyogo. Documento final } \\
\text { resultante da Conferência Mundial de Redução } \\
\text { de Desastres. Kobe, Hyogo, Japão (18 a } 22 \text { de } \\
\text { janeiro de 2005). }\end{array}$ \\
\hline Decreto Municipal n 33.322, de 23/12/2010. & $\begin{array}{l}\text { Cria o Centro Integrado de Controle Operacio- } \\
\text { nal - Centro de Operações Rio. }\end{array}$ \\
\hline $\begin{array}{l}\text { Lei Municipal Complementar } n^{\circ} 111, \text { de } \\
01 / 02 / 2011 .\end{array}$ & $\begin{array}{l}\text { Dispõe sobre a Política Urbana e Ambiental do } \\
\text { Município e institui o Plano Diretor de Desen- } \\
\text { volvimento Urbano Sustentável do Município } \\
\text { do Rio de Janeiro. }\end{array}$ \\
\hline Lei Federal $n^{\circ} 12.608$, de 10/04/2012. & $\begin{array}{l}\text { Institui a Política Nacional de Proteção e } \\
\text { Defesa Civil (PNPDC). A lei dispõe sobre o } \\
\text { Sistema Nacional de Proteção e Defesa Civil - } \\
\text { SINPDEC e o Conselho Nacional de Proteção e } \\
\text { Defesa Civil - CONPDEC e autoriza a criação } \\
\text { do sistema de informações e monitoramento } \\
\text { de desastres. }\end{array}$ \\
\hline
\end{tabular}

Organização dos autores 


\section{METODOLOGIA}

A proposta que se desenvolve neste trabalho constitui uma pesquisa descritiva. Teve por objetivo o estudo do Plano de Ação para chuvas torrenciais que impactam o município do Rio de Janeiro principalmente nos meses de verão. O método utilizado baseia-se em revisão de literatura com foco no referencial teórico dos planos de contingência apresentados pela Subsecretaria de Defesa Civil-SUBDEC e o estudo da Organização das Nações Unidas-ONU para "cidades mais resilientes e habitáveis".

\section{O MARCO DE AÇÃO DE HYOGO}

O Brasil passou por um grande marco voltado às questões ambientais quando acolheu em 1992 a Conferência das Nações Unidas sobre meio ambiente e desenvolvimento-RIO-92. Como produto, países signatários passaram a adotar a "Agenda 21 ", documento de compromissos para a incorporação dos princípios do desenvolvimento sustentável. Em 2000, a ONU em parceria com organizações, Estados e a sociedade civil e com intuito de buscar estratégias para a redução dos riscos de desastres instituiu a Estratégia Internacional para a Redução de Desastre - EIRD. Posteriormente houve a implementação do Marco de Ação de Hyogo - MAH (2005-2015), que tinha por objetivo adotar estratégias para a redução das perdas ocasionadas por desastres como vidas humanas, bens sociais, econômicos e ambientais (ONU, 2005; EIRD, 2005; UNISDR, 2005; SANTOS, 2012; SILVA, 2012).

Na ocasião da elaboração do Marco, países participantes estabeleceram um plano de ação de dez anos que visava à redução de riscos de desastres. Dentre as prioridades estavam o fortalecimento e a redução de fatores de risco dentre os quais a ocupação de áreas ambientalmente frágeis, o fortalecimento da preparação para os desastres com a elaboração de planos de contingência e simulados, a fomentação da produção e divulgação de conhecimento sobre desastres e a promoção da identificação das áreas vulneráveis, com a elaboração de mapas de risco. Em junho de 2012 houve na cidade do Rio de Janeiro a Conferência das Nações Unidas sobre Desenvolvimento Sustentável - CNUDS (Rio +20) que reavaliou a implementação do MAH (ANTUNES, 2012).

Em maio de 2012 foi realizado o I Workshop do MAH do Estado do Rio de Janeiro. O Corpo de Bombeiros do Estado - CBMERJ e a Assessoria de Comunicação Social da Secretaria de Estado de Defesa Civil - SEDEC apresentaram os resultados do mapeamento das áreas sob ameaça de ocorrência de desastres naturais. Foram mapeados 460 pontos em 92 municípios. São apresentadas na Figura 1 as maiores ameaças identificadas no estudo. Os deslizamentos representaram $18 \%$ dos casos notificados, seguidos pelas enchentes e alagamentos com $15 \%$ e as enxurradas com 13\% (SEDEC/CBMERJ, 2012).

Figura 1. Mapeamento dos principais desastres naturais que ocorrem no estado do Rio de Janeiro (\%)

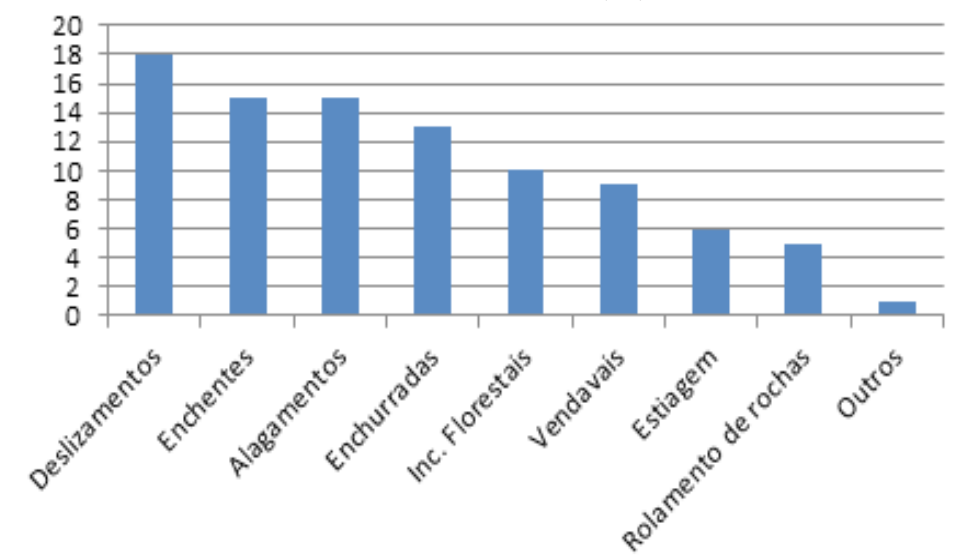

Fonte: SEDEC/CBMERJ, 2012, organização dos autores. 
A resiliência das cidades frente a chuvas torrenciais: Estudo de caso do plano de contingência da cidade do Rio de Janeiro Marisa Fasura de Amorim, Osvaldo Luiz Gonçalves Quelhas, Ana Lúcia Torres Seroa da Motta

\section{A influência do Marco no município do Rio de Janeiro}

Em funcionamento desde 2011, o Centro Nacional de Monitoramento e Alertas de Desastres Naturais - Cemaden vem contribuindo com as Defesa Civil nacional, estaduais e municipais no mapeamento e monitoramento de áreas de riscos. Tem por objetivo reduzir os impactos que possam atingir diretamente aos setores socioambiental e econômico. No Rio de Janeiro, em parceria com a Defesa Civil, auxilia no monitoramento de chuvas torrenciais. Por meio de alertas e em tempo real, áreas de risco monitoradas são avisadas (BARRA, 2011; CEMADEN, 2013).

Com base no MAH a prefeitura do município elaborou o PEM-Rio cujas metas eram priorizar a redução dos riscos de desastres. Conhecer os riscos, adotar medidas preventivas, desenvolver junto à população a compreensão e conscientização da situação, treinando-as e preparando-as para agirem corretamente frente aos riscos eram as metas a serem alcançadas. O Centro de Operações do Município do Rio de Janeiro - CO-Rio passou a ser o responsável pela coordenação da operação (PEM-Rio, 2012; PEM-Rio, 2012).

\section{AS CIDADES E A RESILIÊNCIA}

Resiliência é a habilidade de um sistema de se antecipar e se adaptar às mudanças a fim de manter o controle e a segurança. Inerente aos planos de prevenção e de proteção perante riscos e crises deve ter competência para retornar ao seu estado original depois de submetida a pressões por eficiência (HOLLANAGEL et al., 2007; COSTELLA, 2008; ULTRAMARI; HUMMELL, 2011).

Uma cidade resiliente é aquela onde os desastres naturais são minimizados, os serviços de infraestrutura organizados, obedecendo a padrões e códigos de segurança. Deve possuir um administrador público que garanta uma urbanização sustentável e onde haja a participação da população nas decisões e no planejamento auxiliando na redução dos desastres naturais. Providas de infraestrutura adequada e serviços básicos há um controle quanto à ocupação desordenada em encostas e áreas sujeitas a inundações. Os investimentos são empregados na redução dos riscos e no controle de situações críticas posteriores a estes (BRASIL, 2009; ONU, 2012; FREIRE, 2013). A ONU em 2012 elaborou um Guia para Construção de Cidades mais Resilientes voltadas aos Gestores Públicos Locais. Nele, foram definidas as políticas públicas a serem desenvolvidas para que houvesse a redução dos impactos tornando as cidades mais resilientes e habitáveis. Foram delimitadas pela ONU situações que podem impactar a resiliência das cidades e que deveriam ser observados pelos Gestores Públicos Locais (Tabela 3). 
Tabela 3. Situações e consequências apresentadas no Guia para Gestores Públicos Locais - ONU

\begin{tabular}{|c|c|}
\hline Situação & Consequências \\
\hline $\begin{array}{l}\text { Crescimento das populações urbanas e aumento } \\
\text { de sua densidade. }\end{array}$ & $\begin{array}{l}\text { Interferência direta nos solos e nos serviços, } \\
\text { ampliando as ocupações de planícies costeiras, } \\
\text { ao longo de encostas instáveis e de áreas de } \\
\text { risco. }\end{array}$ \\
\hline $\begin{array}{l}\text { Concentração de recursos e capacidade em } \\
\text { âmbito nacional. }\end{array}$ & $\begin{array}{l}\text { Ausência de fiscalização, recursos humanos } \\
\text { e capacidade do governo local, incluindo or- } \\
\text { dens pouco claras para ações de resposta e de } \\
\text { redução de riscos de desastres. }\end{array}$ \\
\hline Governança local fragilizada & $\begin{array}{l}\text { Participação insuficiente do público de interes- } \\
\text { se local no planejamento e na gestão urbana. }\end{array}$ \\
\hline $\begin{array}{l}\text { Gestão dos recursos hídricos, dos sistemas de } \\
\text { drenagem e de resíduos sólidos inadequados. }\end{array}$ & $\begin{array}{l}\text { Emergências sanitárias, inundações e desli- } \\
\text { zamentos. }\end{array}$ \\
\hline Declínio dos ecossistemas & $\begin{array}{l}\text { Atividades humanas, tais como construção } \\
\text { de estradas, poluição, recuperação das zonas } \\
\text { úmidas e extração insustentável de recursos } \\
\text { que comprometem a capacidade de oferecer } \\
\text { serviços essenciais, como, por exemplo, a } \\
\text { proteção e regulação contra inundações. }\end{array}$ \\
\hline $\begin{array}{l}\text { Deterioração da infraestrutura e padrão de } \\
\text { construção insegura. }\end{array}$ & Podem levar ao colapso das estruturas. \\
\hline Serviços de emergência descoordenados. & $\begin{array}{l}\text { Afetam a capacidade de rápida resposta e } \\
\text { preparação. }\end{array}$ \\
\hline Efeitos adversos das mudanças climáticas. & $\begin{array}{l}\text { Aumento das temperaturas extremas e das } \\
\text { precipitações, na dependência de condições lo- } \\
\text { calizadas, com um impacto sobre a frequência, } \\
\text { a intensidade e a localização das inundações e } \\
\text { outros desastres relacionados ao clima. }\end{array}$ \\
\hline
\end{tabular}

Organização dos autores

Silva (2012) define vulnerabilidade como "o grau de resistência ou suscetibilidade de um sistema socioeconômico em relação ao impacto dos perigos naturais e desastres tecnológicos ou ambientais." É determinada pelo grau de consciência da população, sua condição de vida, a infraestrutura e as políticas públicas relacionadas à gestão de desastres.

\section{O MUNICÍPIO DO RIO DE JANEIRO}

O município do Rio de Janeiro possui 169 bairros distribuídos por uma área de $1.224,46 \mathrm{~km}^{2}$ com 106 km de praias oceânicas e interiores. Seu relevo é composto por uma planície litorânea cercada de morros, com litoral recortado, algumas ilhas, clima tropical e vegetação predominante de mata Atlântica (CARNEIRO; SANTOS, 2012). No Censo realizado em 2010 a cidade do Rio de Janeiro possuía uma população de 6.320 .446 habitantes, representando uma densidade demográfica de 5.163 hab. $/ \mathrm{km}^{2}$ (IBGE, 2013).

Devido a mudanças climáticas ocorridas nos últimos vinte anos a região metropolitana do Rio de Janeiro vem sofrendo com inundações e deslizamentos de terra. Na última década, a temperatura da superfície do mar na região, teve um aumento de aproximada- 
mente $1,5^{\circ} \mathrm{C}$ o que ocasionou uma maior evaporação da água que agregado à brisa do mar trouxe uma maior quantidade de chuvas à cidade. Estudos mostraram um aumento na intensidade e na frequência das chuvas em $11,77 \mathrm{~mm} / \mathrm{ano}$ na Zona da Tijuca. Foi observado que a amplitude térmica diária nesta área está crescendo, aumentando a temperatura máxima do ar a uma taxa mais elevada do que a temperatura mínima em $0,05^{\circ} \mathrm{C} /$ ano. Resultados de estudos indicaram mudanças nos padrões de vento, da circulação da brisa do mar e da terra, e no transporte de umidade para a cidade. Esta tendência pode estar relacionada às mudanças na frequência e duração das frentes frias, visto que a maioria das chuvas nesta região é originada de penetrações de frentes frias (NETO, 2012; DERECZYNSKI et al., 2013).

\section{Histórico de eventos pluviométricos ocorridos na cidade}

O Instituto de Geotécnica do Município do Rio de Janeiro, atual Fundação GEO-RIO, foi criado em 12 de maio de 1966. Ligada à Secretaria Municipal de Obras da Prefeitura, tinha por objetivo atender a demanda ocasionada pelas fortes chuvas ocorridas em janeiro daquele ano que ocasionaram 70 mortos e mais de 500 pessoas feridas. Os trabalhos se iniciaram a partir dos levantamentos das situações de riscos das encostas, devido principalmente aos acidentes geotécnicos ocorridos na ocasião Em fevereiro de 1967, apesar de já terem sido concluídas 39 obras de contenção a cidade voltou a sofrer com as chuvas torrenciais. Casas e ruas foram destruídas e cerca de 100 pessoas morreram em decorrência de acidentes geológicos nas encostas. Vinte e um anos após, em fevereiro de 1988 , novos eventos relacionados a chuvas torrenciais ocorreram na cidade atingindo principalmente o Maciço da Tijuca. Em 24 horas, foram registrados $177 \mathrm{~mm}$ de precipitações pluviométricas ocasionando centenas de acidentes geológicos nas encostas que resultaram em 58 vítimas fatais. Após o evento, além de obras de estabilização e drenagem foi elaborado o primeiro mapa de áreas de risco do Município. Com advento do sistema de informatização houve a implantação de programas pilotos de monitoramento automático, geotécnico e pluviométrico das encostas.
No ano de 1996, precipitações superiores a $190 \mathrm{~mm}$ foram registradas nos bairros da zona sul e oeste da Cidade. Escorregamentos ocorreram em vários trechos dos maciços da Tijuca e da Pedra Branca, destruindo centenas de casa e matando 52 pessoas. Pneus e fibras vegetais passaram a ser utilizados como novas técnicas de contenção. A Cidade passou a contar com um sistema de alerta de chuvas intensas e de deslizamentos em encostas, conhecido como Sistema Alerta Rio (GEO-Rio, 2014).

Enchentes e deslizamentos ocorreram pela cidade ocasionando diversos transtornos devido a um alerta tardio em março de 2000. O índice pluviométrico na ocasião foi superiores a $200 \mathrm{~mm}$, principalmente na zona oeste da cidade (BELASSIANO et al., 2000).

Em abril de 2010, trinta e cinco pessoas morreram devido as fortes chuvas que duraram mais de 36 horas e atingiram o município. Dentre os bairros mais afetados estavam os da Zona Oeste e Norte do município (PORTAL G1, 2010; PORTAL VEJA, 2010). A cidade voltou a sofrer com chuvas em abril de 2011. Durante quatro horas choveu o equivalente a 40 dias. Como resultado a cidade enfrentou alagamentos. Nove comunidades foram avisadas do risco de desabamento por meio das sirenes de alerta. Orientados os moradores procuraram os Pontos de Apoio- PA's da prefeitura (PORTAL G1, 2011).

Em dezembro de 2013, depois de um dia cuja sensação térmica foi de $47^{\circ} \mathrm{C}$, a cidade entrou em estágio de atenção nível três em um escala onde o limite máximo é quatro. Sirenes foram acionadas em sete comunidades e os moradores foram orientados por agentes comunitários e da Defesa Civil a se dirigirem aos pontos de apoio. Em apenas uma hora na região da Grande Tijuca choveu o equivalente a 88 mm. Segundo o Centro de Operações da Prefeitura o protocolo para acionamento das sirenes são para registros superiores a $40 \mathrm{~mm} / \mathrm{h}$ (Portal G1, 2013). As maiores precipitações pluviométricas registradas pelo Sistema Alerta Rio (2014) nas estações no período de uma hora ocorridas nos últimos quatorze anos são apresentados na Tabela 4. 
Tabela 4. Maiores precipitações pluviométricas registradas pelo Sistema Alerta Rio

\begin{tabular}{|l|l|l|}
\hline Estação & $\mathrm{mm} / \mathrm{h}$ & Data \\
\hline Campo Grande & 116,2 & $03 / 2000$ \\
\hline Sumaré & 103,4 & $06 / 2006$ \\
\hline Tijuca/Muda & 99,6 & $04 / 2011$ \\
\hline Campo Grande & 99,1 & $03 / 2000$ \\
\hline Tijuca/Muda & 97,8 & $04 / 2011$ \\
\hline Copacabana & 93,6 & $01 / 2003$ \\
\hline Ilha do Gover. & 93,4 & $12 / 2010$ \\
\hline Barra/Riocentro & 92,6 & $06 / 2006$ \\
\hline Tijuca/Muda & 92,2 & $12 / 2013$ \\
\hline Copacabana & 90,4 & $01 / 2003$ \\
\hline
\end{tabular}

Organização dos autores.

Cálculos da prefeitura indicam que há 13 mil famílias vivendo em áreas de risco. O Rio de Janeiro e os grandes centros urbanos terão que conviver nos próximos anos com mudanças climáticas tais como chuvas torrenciais, grandes enchentes e temperaturas extremas. Segundo Carlos Nobre, secretário do Ministério da Ciência, Tecnologia e Inovação (MCTI) e membro do Painel Intergovernamental sobre Mudanças Climáticas (IPCC) da ONU, as cidades deverão se antecipar e adaptar-se as mudanças para suportar este tipo de impacto. Para o Prof. ${ }^{\circ}$ Barbieri do Departamento de Demografia da Universidade Federal de Minas Gerais, os trabalhos acadêmicos existentes e futuros poderão auxiliar no mapeamento da vulnerabilidade às mudanças climática no município (TORRES, 2014).

\section{Características pluviométricas do município}

Até a década de 1970, o município do Rio de Janeiro tinha uma rede composta por vinte postos de estações pluviométricas distribuídos em sua maior parte ao norte da cidade. Não havia postos na baixada de Jacarepaguá ou nos maciços e, somente a zona sul da cidade possuía estações no litoral. No ano de 2006 já haviam espalhadas pelo município 32 estações pluviométricas sendo sua maior área de concentração no Maciço da Tijuca, conforme apresentado na Figura 2. Esta nova distribuição auxiliou no atendimento ao sistema de alerta de chuvas intensas. (DERECZYNSKI et al., 2009).

Figura 2. Estações pluviométricas do município

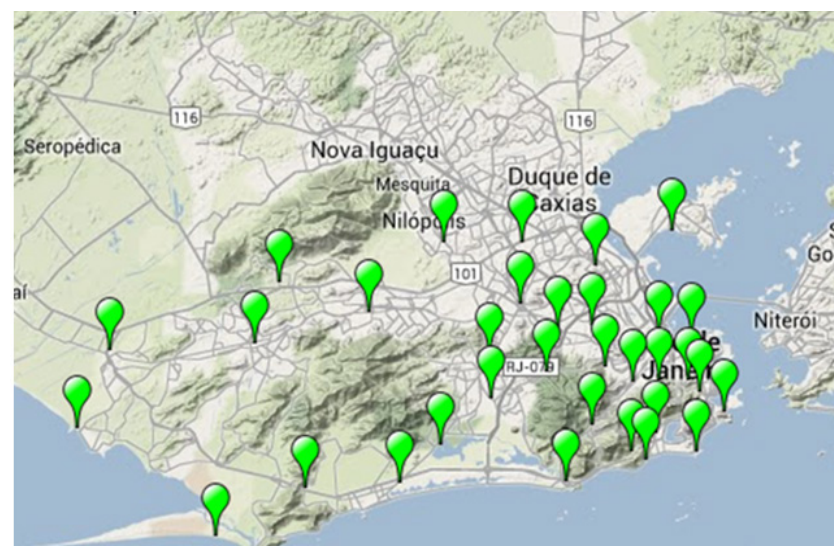

Fonte: Climatempo (2014), adaptado pelos autores. 
Estudos constataram que entre os meses de novembro e março costumam ocorrem $81,3 \%$ do total das precipitações pluviométricas anuais. Dependendo de suas características físicas, as chuvas ocasionam um efeito erosivo no solo. $O$ estudo da relação causa $x$ efeito é fundamental para o planejamento conservacionista dos solos. Além dos problemas ambientais como o assoreamento dos rios e a redução da fertilidade do solo a chuva é considerada como o fator mais ativo da erosão hídrica. A ocupação urbana irregular pode provocar a redução da capacidade de interceptação da chuva pela cobertura vegetal potencializando a erosão e os alagamentos, pois não há um planejamento urbano adequado com gerenciamento de riscos e prevenção a desastres. No Rio de Janeiro as características da cidade colaboram para que haja uma tendência para a ocorrência de deslizamentos (MACHADO et al., 2008; GUERREIRO et al., 2010; TOGASHI, 2012; ROLNIK, 2014).

Com o objetivo de determinar um valor limite para classificação de eventos de chuvas intensas no município do Rio de Janeiro, Dereczynski et al. (2009) elaboraram uma analise entre o período compreendido de janeiro de 1997 a dezembro de 2006. No estudo, foram calculados os percentis sobre os totais pluviométricos diários para cada um dos trinta postos existentes. A análise revelou uma grande variabilidade da precipitação no município com picos elevados como na região do Sumaré $(92,3 \mathrm{~mm})$ se comparado com a região da Penha $(34,7 \mathrm{~mm})$ conforme apresentado na Figura 3. Em todas as estações pluviométricas estudadas foram calculadas as precipitação correspondente ao percentil 99, superior a 30,0 $\mathrm{mm}$. Para que fossem considerados eventos de precipitação intensa os índices pluviométricos diários deveriam ser iguais ou superiores a $30,0 \mathrm{~mm}$ em pelo menos cinco estações. A técnica utilizada, percentis, revelou que índices inferiores não representavam características para classificação como chuva intensa. A pesquisa revelou também que as estações do ano mais chuvosas eram o verão e a primavera e que o período noturno tinha maior tendência de concentração de eventos de chuva devido principalmente ao maior aquecimento local nesta época do ano (DERECZYNSKI et al., 2009).

Figura 3. Cálculo diário das precipitações correspondente ao percentil 99 na cidade do Rio de Janeiro no período compreendido de janeiro de 1997 a dezembro de 2006

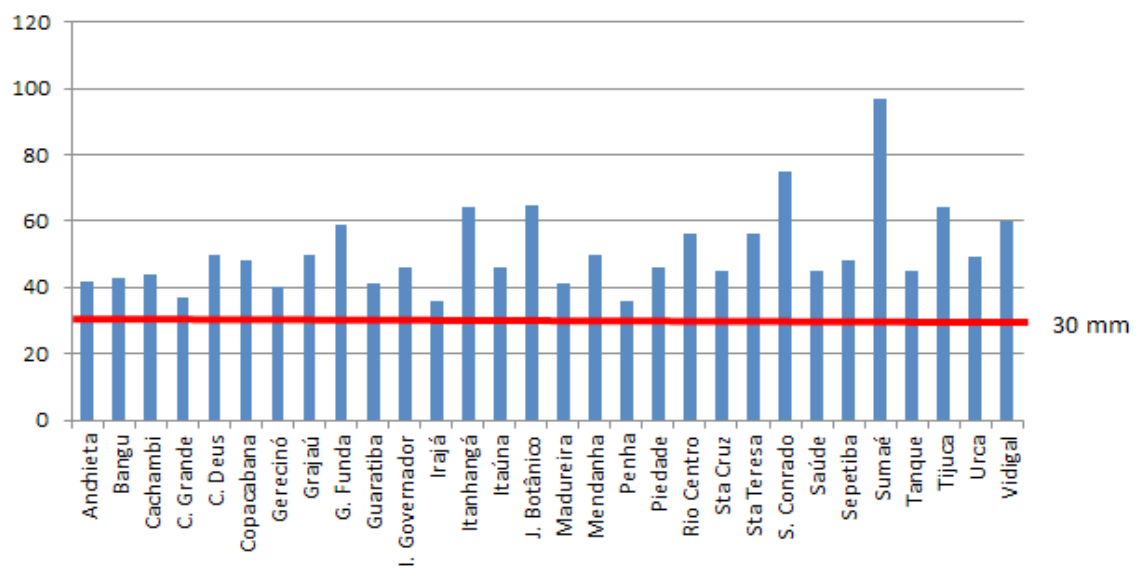

Organização dos autores.

\section{O PLANO DE CONTINGÊNCIA}

Plano de Contingência é o conjunto de procedimentos e ações para situações de risco e emergências ocasionadas por fenômenos de natureza geológico, geotécnico e hídrico que possam ocasionar a perda de vidas. Tem por objetivo definir as ações emergenciais a serem tomadas em caso de constatação de risco iminente. Os Planos devem ser operacionalizados preferencialmente nos períodos mais chuvosos onde 
há maior probabilidade de deslizamentos (SEF, 2011; PCDC, 2012; BRASIL, 2012). Para o CENAD (2012), um Plano de Contingência deve ter por objetivo orientar, definir e organizar as ações a serem executadas pelos órgãos que compõem o Sistema de Defesa Civil de cada município. Dentro deste contexto, o Programa de Gestão de Riscos e Resposta a Desastres - PGRRD, atenta para a necessidade de observação quanto às circunstâncias dos eventos adversos ou desastres naturais principalmente relacionados com o incremento de precipitações hídricas que possam ocorrer nas cidades. Todo o processo deverá ter um planejamento quanto ao emprego de recursos disponíveis, com grupos de atividades coordenadas composto por dirigentes e/ou servidores dos diversos Órgãos Municipais, Estaduais e Federais, sob a Coordenação da Coordenadoria Municipal de Defesa Civil.

Para reforçar esta necessidade a Lei Federal $\mathrm{n}^{\mathrm{o}}$ 12.608, de abril de 2012 instituiu a Política Nacional de Proteção e Defesa Civil - PNPDEC que dispõe sobre o Sistema Nacional de Proteção e Defesa Civil - SINPDEC e sobre o Conselho Nacional de Proteção e Defesa Civil - CONPDEC, autorizando a criação do sistema de informações e monitoramento de desastres.

\section{O Plano de Contingência do município}

Mapeamento realizado pela prefeitura do Rio de Janeiro em 2011, em 52 bairros, identificou 21 mil moradias em áreas de alto risco em 117 comunidades das 196 pesquisadas. As maiores concentrações populacionais evidenciadas foram no Maciço da Tijuca e na Serra da Misericórdia. O estudo foi realizado a partir de uma radiografia da suscetibilidade de escorregamentos de encostas que pudessem atingir a população que ocupava morros e áreas de encosta. Como política e resposta a situação encontrada a prefeitura estabeleceu que fossem realizadas obras para contenção de encostas em áreas de risco (ORITZ, 2011). A partir da coleta de dados a prefeitura do Rio de Janeiro em parceria com a Defesa Civil adotou medidas preventivas com a implementação de um Plano de Desocupação. Teve por base o Relatório de Correlação entre Chuvas e Escorregamentos para a Cidade do Rio de Janeiro ocorridas no ano de 2012 - Relatório GEO-Rio/DEP/ GPE (2013). Como prioridades para o PEM-Rio-2013, foram adotadas medidas preventivas conforme apresentado na Tabela 5.

Tabela 5. Prioridades do PEM-Rio-2013

\begin{tabular}{|l|l|}
\hline Implementação & Medida adota \\
\hline Radar Meteorológico & $\begin{array}{l}\text { Fortalecimento da Defesa Civil e demais ór- } \\
\text { gãos do Sistema e a implantação do Centro de } \\
\text { Operações }\end{array}$ \\
\hline Sistema de Alerta e Alarme Comunitário (A2C2) & Mapeamento das áreas de risco geológico. \\
\hline Núcleos Comunitários de Defesa Civil & $\begin{array}{l}\text { Entendimento e conscientização. Atuação em } \\
\text { escolas por meio de eventos e simulaçóes reali- } \\
\text { zados pela prefeitura em parceria com a Defesa } \\
\text { Civil Municipal }\end{array}$ \\
\hline Reassentamento de moradores & $\begin{array}{l}\text { Reduzir os riscos delimitando legal e fisicamente } \\
\text { as áreas. Ações contínuas de conservação e lim- } \\
\text { peza de encostas, realização de reflorestamento } \\
\text { e de obras de infraestrutura e estabilização de } \\
\text { encostas }\end{array}$ \\
\hline Plano de Emergência & $\begin{array}{l}\text { Definir atribuições e responsabilidades em } \\
\text { parceria com a comunidade, sociedade civil } \\
\text { e poder público. Simulações de desocupação } \\
\text { emergencial das comunidades. }\end{array}$ \\
\hline
\end{tabular}

Fonte: PEM-Rio (2013), organização dos autores.

Soc. \& Nat., Uberlândia, 26 (3): 519-534, set/dez/2014 
Em 2011 havia cerca de 1.800 agentes comunitários capacitados pela Defesa Civil para atuarem em 25 favelas atendendo a cerca de $40 \%$ das famílias moradoras de áreas de risco. Com intuito de ampliar esta rede, a Defesa Civil capacitou neste mesmo ano mais 85 representantes de associações de moradores de áreas de risco, fornecendo cartilhas, um telefone celular de comunicação com a rede da prefeitura e treinamento que incluía a colaboração da população em casos de emergência. Segundo a prefeitura, no ano de 2010 foram realizadas obras de beneficiamento de áreas críticas em 47 comunidades, com previsão para 2011 de atender 27 comunidades e, nos anos seguintes quarenta e três (ORITZ, 2011).

Como ação direta, o PEM-Rio (2012) visava deslocar temporariamente os moradores para locais seguros, denominados Pontos de Apoio- PA. Para a Defesa Civil, estes locais não serviriam como abrigo, pois eram considerados locais de passagem onde os moradores poderiam permanecer por um curto período de tempo garantindo sua integridade física até a passagem do perigo.

\section{Respostas do município em busca da resiliência às chuvas fortes}

A partir de estudos realizados e do mapeamento dos riscos no município, a Defesa civil em parceria com a prefeitura direcionou o monitoramento e a priorização das ações de preparação dos moradores para o sistema A2C2 e em especial para o Sistema de Alarme por Sirenes (ORITZ, 2011; GEO-Rio, 2013). Núcleos Comunitários de Defesa Civil - NUDEC's. foram implementados em 2010 passando a atuar como elo entre a comunidade e a Defesa Civil. Um radar meteorológico com alcance de $250 \mathrm{~km}$ passou a atuar em dezembro do mesmo ano integrando o Sistema Alerta Rio. Todo controle é realizado no Centro de Operações - CO que atuava em regime de 24 horas. O monitoramento é realizado a partir da leitura de 36 pluviômetros espalhados por diversas regiões da cidade. Após analise é definido o nível de alerta conforme apresentado na Tabela 6 (PEM - Rio, 2012).

Tabela 6: Níveis de alerta e estágios das precipitações

\begin{tabular}{|c|c|c|c|}
\hline Cor & Nível & Descrição da situação & $\begin{array}{l}\text { Intensidade } \\
(\mathrm{mm} / \mathrm{h})\end{array}$ \\
\hline Verde & Vigilância & $\begin{array}{l}\text { Ausência de chuvas ou } \\
\text { chuvas leve nas } \\
\text { próximas } 6 \text { horas. }\end{array}$ & 1,1 a 5,0 \\
\hline Amarelo & Atenção & $\begin{array}{l}\text { Possibilidade de chuvas } \\
\text { moderada, } \\
\text { ocasionalmente forte, } \\
\text { nas próximas horas. }\end{array}$ & 5,1 a 25 \\
\hline Vemelho & Alerta & $\begin{array}{lr}\text { Chuvas fortes } & \text { nas } \\
\text { próximas } & \text { horas, } \\
\text { podendo } & \text { causar } \\
\text { alagamentos } & \text { e } \\
\text { deslizamentos isolados. }\end{array}$ & 25,1 a 50 \\
\hline Preto & $\begin{array}{l}\text { Alerta } \\
\text { Máximo }\end{array}$ & $\begin{array}{lr}\text { Chuva muito } & \text { forte nas } \\
\text { próximas } & \text { horas, } \\
\text { podendo } & \text { causar } \\
\text { alagamentos } & \text { e } \\
\text { deslizamentos } & \\
\text { generalizados. } & \end{array}$ & $>50$ \\
\hline
\end{tabular}

Fonte: PEM-Rio (2012), organização dos autores. 
O Plano é acionado caso exista previsão de chuvas fortes seguindo uma estratégia operacional conforme apresentado na Figura 4. Por meio de um canal gratuito e direto junto às operadoras de telefonia móvel os responsáveis pelos PA's são avisados via SMS (Short Message Service).

Figura 4. Estratégia operacional

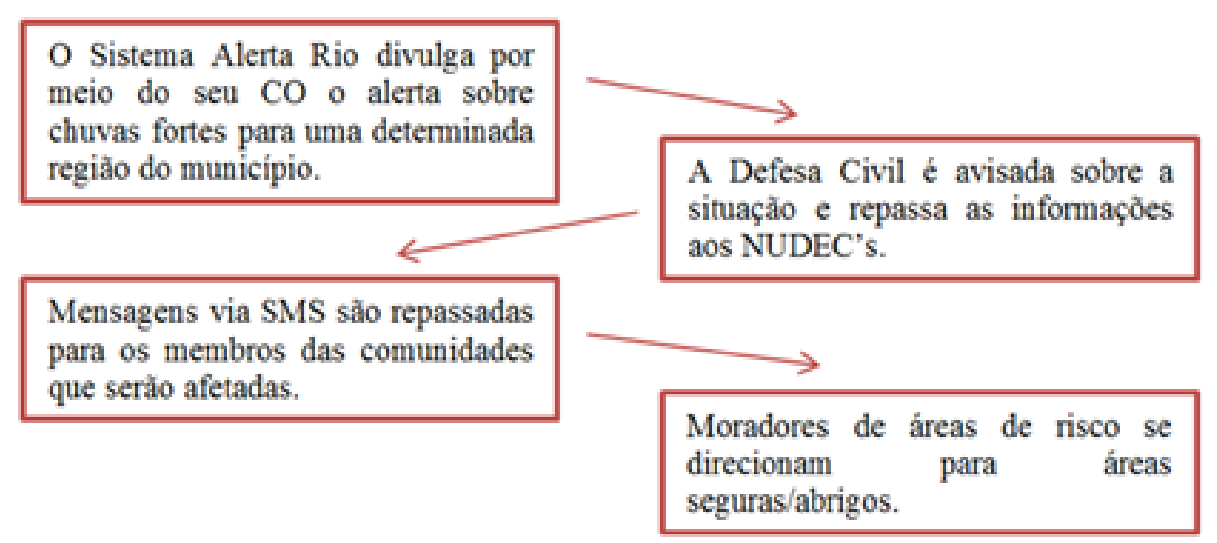

Elaboração dos autores.

Segundo a prefeitura, em dezembro de 2011 haviam 3.653 agentes comunitários que eram periodicamente reciclados, distribuídos em 569 NUDEC's. Para consolidar o sistema A2C2 no ano de 2011 foi instalado pela prefeitura 66 sirenes em comunidades que tinham edificações em áreas de alto risco. No ano seguinte foram instaladas mais 35 sirenes. Seu acionamento é realizado remotamente pelo CO. Caso não funcione, este é acionamento manual por meio de uma chave mestra que fica de posse dos Líderes Comunitários ou pessoas responsáveis por cada PA. (PEM-Rio; 2012)

Nos últimos cinco anos houve um investimento no município em obras de contenção de encosta no valor de US\$ 190,50 milhões, superando o investimento ocorrido entre os anos de 2001 a 2008 que foi de US\$ 41 milhões. Entre as obras estão o Piscinão da Praça da Bandeira construído para o controle de enchentes da região da Grande Tijuca e o sistema de drenagem para conter a elevação do nível do mar na zona portuária (TORRES, 2014). Em relatório técnico apresentado pelo CREA-RJ, em janeiro de 2014, foram apresentadas como solução para os problemas das enchentes que afetam os rios do estado à intervenção nas bacias para retenção das águas, o saneamento do esgoto, o reflorestamento das margens e encostas, o aumento da permeabilidade do solo, e a coleta permanente de lixo nos bairros e locais ribeirinhos (IDALGO, 2014).

\section{CONCLUSÃO}

O Estado do Rio de Janeiro é um dos mais afetados por inundações, enxurradas, enchentes e alagamentos. O aumento de ocorrências de desastres é em sua maioria, devido à ocupação inadequada de áreas de risco geológico. Assentamentos precários e a ausência de infraestrutura urbana ligada à falta de um sistema de drenagem, agregado ao lixo nas encostas e a fragilidade das construções, potencializam os riscos principalmente nos períodos chuvosos (CENAD, 2012). O município do Rio de Janeiro quando afetado por precipitações intensas tem seu fluxo de transportes e serviços essenciais como energia elétrica, saneamento básico, distribuição de água potável, coleta do lixo e comunicações telefônicas comprometidas. Devido ao seu tamanho e representatividade o estudo da climatologia das precipitações é de grande importância para o município, pois pode afetar diretamente a indústria, $o$ comércio e ao próprio planejamento urbano (DERECZYNSKI et al., 2009; PEM-Rio, 2012).

O PEM-Rio vem se atualizado anualmente para atender as novas demandas existentes. A preparação dos moradores das comunidades e a implantação 
A resiliência das cidades frente a chuvas torrenciais: Estudo de caso do plano de contingência da cidade do Rio de Janeiro Marisa Fasura de Amorim, Osvaldo Luiz Gonçalves Quelhas, Ana Lúcia Torres Seroa da Motta

do $\mathrm{A} 2 \mathrm{C} 2$ são medidas fundamentais para a redução dos desastres e impactos nas comunidades e na cidade. A Defesa Civil tem realizado treinamentos e planos de ação para minimizar tais impactos. A construção do entendimento e da consciência junto à população e das autoridades competentes quanto a projetos voltados as necessidades locais poderão trazer resultados positivos (PEM-Rio, 2012; PEM-Rio, 2013). Os trabalhos preventivos realizados pela Defesa Civil em parceria com a prefeitura do Rio de Janeiro nos últimos quatro anos trouxeram mudanças segundo o Superintendente Operacional da Defesa Civil, Cel. Santos. Segundo o coronel, neste período não houve óbitos devido a desmoronamento de encostas. Nos anos anteriores houve um trabalho intenso para que houvesse a redução deste número. Os alarmes das sirenes atuaram de maneira preventiva e positiva. Entretanto situações de enchentes vivenciadas pelo município ainda não foram totalmente solucionadas $(\mathrm{G} 1,2013)$.

Pesquisas apontaram um aumento de eventos relacionados às chuvas intensas, principalmente na região de floresta da Zona da Tijuca. As análises desses eventos são de extrema importância, pois, podem apoiar estudos futuros relacionados à vulnerabilidade e aos impactos provocados nas cidades, preparando-as estrategicamente para às mudanças climáticas. Este tipo de evento afeta diretamente a economia. O conhecimento das tendências futuras ajudará na elaboração de estratégias de gestão dos riscos associados a eventos extremos para elaboração de um plano de contingência voltado a esta necessidade (DERECZYNSKI et al., 2009; GUERREIRO, et al. 2010).

A atuação pública nas comunidades deve não só criar estratégias para esquemas de alerta e evacuação rápida. Devem ter por base obras de infraestrutura e planos de contingência. (BAUTÈS, 2008; ROLNIK, 2014). Estudos com bases científicas poderão auxiliar quanto às incertezas inerentes às mudanças climáticas que possivelmente virão a ocorrer auxiliando cada município a prever e minimizar os impactos que atingem principalmente aos moradores das áreas de risco.

\section{AGRADECIMENTOS}

A primeira autora agradece a Coordenação de Aperfeiçoamento de Pessoal de Nível Superior
(CAPES) pelo suporte financeiro através da bolsa de capacitação.

\section{REFERÊNCIAS}

ANTUNES, André. Desastres Naturais? Interfaces entre Defesa Civil, saúde e meio ambiente. Revista Cidadania \& Meio Ambiente. Abr. 2012. Disponível em: < http://www.ecodebate.com.br>. Acesso em: 12 ago.2013.

BARRA, Mário. Centro Nacional passa a operar 24 horas a partir deste sábado. Portal G1. 17 dez. 2011, São Paulo. Disponível em:< http://g1.globo.com>. Acesso em: 24 abr. 2013.

BAUTÈS, Nicolas. Para além do espetáculo: resiliência e desvios em torno de um projeto de valorização de favela. In: BAUTÈS, Nicolas. Interlocuções Urbanas: arenas, enredos e atores. Ed. Arco Iris, 2008. p 111121. Disponível em: $<$ http://hal.archives-ouvertes.fr >. Acesso em: 02 mar. 2014.

BELASSIANO, Marcelo; LIMA, Shirley Marques; Barbosa, Marisa Carvalho Durão; MARQUES, Bruno Pinto; SILVA, Maria Gertrudes Alvarez Justi da. Sist. de Al. de Chuvas intensas na cidade do R. de Jan.: Eventos do verão 1999/2000. In: XI CONGRESSO BRASILEIRO DE METEOROLOGIA. Rio de Janeiro, 2000. Anais... Rio de Janeiro, 2000. Disponível em: $<$ http://www.cbmet.com $>$. Acesso em 07 mar. 2014.

BRASIL. Lei Federal no 12.608, de 10/04/2012. Institui a Política Nacional de Proteção e Defesa Civil - PNPDEC. Brasília. 2012. Disponível em:< http:// www.planalto.gov.br/>. Acesso em: 23 abr. 2013.

BRASIL (Ministério da Ciência e Tecnologia). Centro Nacional de Monitoramento e Alertas de Desastres Naturais. CEMADEN (Página na internet) 2013. Disponível em: $<$ http://www.cemaden.gov.br/historico. php>. Acesso em: 01 jun.2013.

BRASIL. (Ministério da Integração / Secretaria Nacional de Defesa Civil). Centro Nacional de Ge- 
renciamento de Riscos e Desastres. CENAD (Página na internet) 2012. Disponível em: $<$ http://www.integracao.gov.br/>. Acesso em: 28 jul. 2013.

CARNEIRO, Alcides; SANTOS, Lucia. A cidade do Rio de Janeiro no contexto demográfico metropolitano em 2010. Notas Téc. Inst. Mun. de Urb. Pereira Passos. Rio de Janeiro, n.10. 2012. Disponível em: < http://www.armazemdedados.rio.rj.gov.br>. Acesso em 01 jun.2013.

CORTESE, Tatiana Tucunduva Philippi. Mudanças Climáticas na Cidade de São Paulo: avaliação da política municipal. Tese (doutorado em Saúde Pública), USP, 2013. São Paulo, 2013. Disponível em:< file://C:/Users/Sony/Downloads/TESE_ TTPC_2013.pdf>. Acesso em: 01 mar. 2014.

COSTELLA, Marcelo Fabiano. Método de avaliação de sistemas de gestão de segurança e saúde no trabalho com enfoque na engenharia de resiliência. Tese (doutorado em Engenharia de Produção), UFRGS, 2008. Porto Alegre, 2008. Disponível em: $<$ http://www.lume.ufrgs.br/handle/10183/13479>. Acesso em: 02 fev. 2014.

DAMÉ, Rita de C. F.; TEIXEIRA, Claudia F. A.; BACELAR, Luiz C. S.; WINKLER, Antoniony S.; SANTOS, Jacira P. dos. Tendência monotônica e pontos de mudança na precipitação no sul do Brasil. Eng. Agric. Jaboticabal, vol.33, n.2, p. 258-268, 2013. Acesso em: 26 fev. 2014. DOI: http://dx.doi. org/10.1590/S0100-69162013000200005

DERECZYNSKI, Claudine Pereira; OLIVEIRA, Juliana Silva de; MACHADO, Christiane Osório. Climatologia da precipitação no Município do Rio de Janeiro. Revista Brasileira de Meteorologia, v.24, n.1, p.24-38, 2009. DOI: http://dx.doi.org/10.1590/ S0102-77862009000100003

DERECZYNSKI, Claudine; SILVA, Wanderson Luiz; MARENGO, José. Detection and Projections of Climate Change in Rio de Janeiro, Brasil. American Journal of Climate Change. Vol.2, No.1, 2013, 9 p. DOI: 10.4236/ajcc.2013.21003
FREIRE, Neison Cabral. Vulnerabilidade x Resiliência em Cidades Brasileiras. Fundação Nacional de Saúde. IV SEMINÁRIO INTERNACIONAL DE ENGENHARIA DE SAÚDE PÚBLICA. Belo Horizonte, 2013. Anais... Belo Horizonte, 2013. Disponível em:< http://www.funasa.gov.br>. Acesso em: 02 mar. 2014.

GUERREIRO, Maria João; LAJINHA, Teresa; ABREU, Isabel. Precipitation indices trends and correlations at a raingauge station in Portugal. Revista da Fac. de Ciências e Tecn. Porto. no 7, p. 44-56, 2010. Disponível em: <http://file.scirp.org/Html/32360053_29084.htm>. Acesso em: 26 fev. 2014.

HOLLNAGEL, Erik; WOODS, David D.; LEVESON, Nancy (Ed.). Resilience Engineering (Ebk): Concepts and Precepts. Ashgate Publishing, 2007.

IDALGO, Renata. CREA-RJ apresenta relatório técnico sobre a situação de rios do Estado considerados pontos críticos de enchentes. Jornal do CREA-RJ. Rio de Janeiro, Ano II. Edição no 16. p.4 e 5, 2014.

LUCENA, Andrews José de; ROTUNNO FILHO, Otto Corrêa; FRANÇA, José Ricardo de Almeida; PERES, Leonardo de Faria; XAVIER, Luciano Nóbrega Rodrigues. Urban climate and clues of heat island. Events in the metropolitan area of Rio de Janeiro. Springer Science. Theor Appl Climatol. Vol. 111 , Issue 3-4 , pp 497-511, 2012.DOI: 10.1007/ s00704-012-0668-0

MACHADO, Roriz Luciano; CARVALHO, Daniel Fonseca de; COSTA, Janaina Ribeiro, OLIVEIRA NETO, Dionízio Honório de; PINTO, Marinaldo Ferreira. Análise da erosividade das chuvas associada aos padrões de precipitação pluvial na região de Ribeirão das Lajes (RJ). Revista Brasileira de Ciência do Solo, vol.32, n.5, p.2113-2123, 2008. DOI: http://dx.doi. org/10.1590/S0100-06832008000500032.

MARENGO, José Antônio. Água e mudanças climáticas. Estudos Avançados vol.22 no.63.2008. Disponível em: $<$ http://www.scielo.br/pdf/ea/v22n63/ v22n63a06.pdf>. Acesso em: 26 fev. 2014. 
A resiliência das cidades frente a chuvas torrenciais: Estudo de caso do plano de contingência da cidade do Rio de Janeiro Marisa Fasura de Amorim, Osvaldo Luiz Gonçalves Quelhas, Ana Lúcia Torres Seroa da Motta

NETO, Giovanni Dolif. Previsão de extremos de chuva no Rio de Janeiro: melhorias utilizando o conhecimento adquirido com eventos anteriores. Tese (doutorado em Meteorologia), INPE, 2012. São José dos Campos, 2012. Disponível em: $<$ http://mtc-m19.sid. inpe.br/col/sid.inpe.br/mtc-m19/2012/03.29.22.41/ doc/publicacao.pdf $>$. Acesso em: 15 mar. 2014.

OLIVEIRA, Alzira_Marques. Indicadores de vulnerabilidade e risco socioambiental para prevenção e mitigação de desastres naturais na Bacia do Rio Jari. Dissertação (mestrado em Dir. Amb. Pol. Púb.), UNIFAP, 2011. Macapá, 2011. Disponível em: <http:// www2.unifap.br/>. Acesso em: 28 fev. 2014.

ONU (Organização das Nações Unidas). A Estratégia Internacional para a Redução de Desastres - EIRD. Disponível em: $<$ http://www.integracao.gov.br/ $>$. Acesso em: 21 mar.2013.

ONU (Organização das Nações Unidas). Como Construir Cidades Mais Resilientes. Um Guia para Gestores Públicos Locais. Escritório das nações Unidas para Redução de Riscos de Desastres. Genebra. Nov. 2012. Disponível em: <http://www.unisdr.org/ > . Acesso em: 24 abr. 2013.

ORTIZ, Fabiola. Rio de Janeiro tem 21 mil moradias e 117 favelas em áreas com alto risco de deslizamento. UOL Notícias RJ. Chuvas pelo Brasil. 06 jan. 2011. Disponível em: $<$ http://noticias.uol.com.br/ $>$. Acesso em 08 mar. 2014.

PIVETTA, Marcos. Da garoa à tempestade. Temporais se tornam mais frequentes e chuvas aumentam 30\% em São Paulo em 80 anos. Revista Pesquisa FAPESP. Edição 195. Maio de 2012. Disponível em: $<$ http:// revistapesquisa.fapesp.br>. Acesso em: 15 mar. 2014.

PORTAL G1. Sobe para 3 número de mortos devido às chuvas no estado do RJ. Portal G1. (Sítio na internet). Edição do Rio de Janeiro. 12 dez 2013. Disponível em:< http://g1.globo $>$. Acesso em: 15 mar. 2014.

PORTAL G1. Temporal provoca noite de caos no Rio após dia de termômetros a $39,8^{\circ}$ C. Portal G1. (Sítio na internet). Edição RJ. 06 dez 2013. Disponível em:< http://g1.globo>. Acesso em 15 mar. 2014.

PORTAL VEJA. Chuvas no Rio de Janeiro. Mais de 250 mortos. Portal Veja. (Sítio na internet) 2010. Disponível em:< http://veja.abril.com.br/>. Acesso em: 15 mar. 2014.

RIO DE JANEIRO (Prefeitura Municipal). I Workshop Est. sobre o Marco de Ação de Hyogo. Rio de Janeiro. ago. 2012. Disponível em: $<$ http://www.cbmerj.rj.gov. br/>. Acesso em: 21 mar. 2013.

RIO DE JANEIRO (Prefeitura Municipal) GEO-RIO. Relatório GEO-RIO/DEP/GPE - No 05/2013. Disponível em:< http://www0.rio.rj.gov.br/ $>$. Acesso em: 25 maio 2013.

RIO DE JANEIRO (Prefeitura Municipal). Plano de Contingência. Verão 2013/2014. Subsecretaria de Defesa Civil. Rio de Janeiro. 2012. Disponível em: $<$ http://www.formulariosonline.com.br- $>$. Acesso em: 20 abr. 2013

ROLNIK, Raquel. Os riscos do risco. Folha de São Paulo. São Paulo. 13 jan. 2014. Disponível em:< http://www1.folha.uol.com.br>. Acesso em: 23 fev. 2014.

SANTOS, Antonio Marcos dos; GALVÍNCIO, Josicleda Domiciano; MOURA, Magna Soelma Bezerra de. Os recursos hídricos e as mudanças climáticas: discursos, impactos e conflitos. Revista Geográfica Venezolana. Vol. 51 (1), p. 59 (10), 2010. Disponível em: < http://www.saber.ula.ve/>. Acesso em: 26 fev. 2014.

SANTOS, Rúbia dos. Gestão de Desastres e Politicas de Assistência Social: Estudo de caso de Blumenaul $S C$. Tese (Doutorado em Sociologia Política), UFSC, 2012. Florianópolis, 2012, Disponível em: $<\mathrm{https} / / /$ repositorio.ufsc.br>. Acesso em: 14 mar. 2014.

SILVA, Carlos Henrique Tomé. Desastres naturais e Desenvolvimento Sustentável. Núcleo de Estudos e Pesquisas do Senado Federal. Brasília, 2012. Dis- 
ponível em: $<$ http://www12.senado.gov.br/>. Acesso em 14 mar. 2014.

TOGASHI, Henrique Fürstenau; MONTEZUNA, Rita de Cásia; LEITE, Adriana Filgueira. Precipitações incidentes e fluxo de atravessamento das chuvas em três sucessionais de floresta Atlântica no maciço da Pedra Branca, Rio de Janeiro. Revista Árvore. Viçosa, v.36, n.5, p.907-917, 2012. DOI: http://dx.doi.org/10.1590/ S0100-67622012000500013

TORRES, Bolívar. Adaptar para sobreviver. O Globo. (Jornal). Rio de Janeiro. 25 fev. 2014. p. 12.

ULTRAMARI, Clovis; HUMMELL, Beatriz. Sobre la geografia de los fenómenos naturales y sus relaciones com mas vulnerabilidades em Brasil. Quivera. vol. 13, núm. 2, julio-diciembre, 2011, pp. 14-33. Universidad Autónoma del Estado de México. México. Disponível em: $<$ http://www.redalyc.org $>$. Acesso em: 09 mar. 2014. 